\title{
Bicycle ownership, use, and injury patterns among elementary schoolchildren
}

\author{
Julian A Waller
}

\begin{abstract}
This paper is the fifth in a series of Injury Classic. Our goal is to reprint one such paper in each issue to initiate newcomers to the field to these old, often quoted, and important contributions. As many are difficult to find, it should help all of us to have a copy at hand. Your suggestions about future articles are welcome. Write to the editor with details of your favourite, most quoted paper.
\end{abstract}

\begin{abstract}
Patterns of bicycle ownership and injury were studied over a four month period among over 6000 schoolchildren. Two thirds of the bikes owned were standard style and one third high rise. Boys more of ten had high rise bikes. Slightly over $2 \%$ of bike owners are injured annually, but no differences were found according to bike style either in injury rate or severity. Bike borrowing and riding double were common factors in the injury events. Injury from spokes and loss of control because of loose handlebars were identified as problems resulting from product design.

(Pediatrics 1971; 47: 1042-1050)
\end{abstract}

Keywords: bicycles, injury, accidents, risk taking behavior.

Although the widespread use of bicycles goes back at least a century, and although they are owned by nearly all children and many adults, there has been a striking dearth of serious study of the ownership and use of bicycles by young children, and of the injuries resulting therefrom. A recent change in bicycle usage has made such study imperative. In the mid-1960s a new style of bicycle - the high rise bike began to appear on the market. This bike has a small front wheel, elongated handlebar projecting vertically instead of horizontally as with standard bikes, and an elongated, 'banana' seat. Some also have a 'sissy' or balancing bar behind the seat projecting up from 2 in to $2 \mathrm{ft}$ above the level of the seat. The new bike presumably is more maneuverable and permits children to play a wider range of games. This new style has rapidly captured the market.

However, in 1968 Howell, ${ }^{1}$ based on his clinical experience, reported a marked increase both in the frequency and the severity of injuries to bike riders since the introduction of the high rise bike on the market. These injuries, he noted, resulted from falls to children who could easily control standard model bikes but who lost control while riding these bikes. In England the Royal Society of Prevention of Accidents also expressed concern about the safety of the new style of bike and referred to it as 'gimmicky.'

The present study grew out of a concern that the injury potential of this new product - just as of any new product - should be evaluated. It is quite conceivable that high rise bikes do represent a new hazard as described above. It is equally possible that the new style, on really careful evaluation, would turn out not to be a problem. Furthermore, if one bike is associated with greater frequency or severity of injury, or both, this may be the result of the style of bike, the fact that it is used by more active or daring children, that the daily number of hours of use per child is greater for this style of bike (in the case of greater frequency of injury), or a combination of these factors.

\section{Method}

The study was limited to bicycle owners and persons injured on bikes in the Greater Burlington, Vermont, area who were between the ages of 3 and 12 years, since almost all high rise bikes are owned by persons in this age range. Four separate steps were involved in the study.

(1) During the 1969 registration of bicycles by the South Burlington Police Department, questionnaires were given to 380 consecutive individuals of the 1092 persons who registered bikes. Fifty nine per cent of the questionnaires were returned, and $67 \%$ of these indicated that the bike was owned by a person aged 12 or younger. The questionnaires contained information about bike style, duration of ownership, age at which the child began riding a bicycle, and medically treated injuries involving bikes.

(2) During October and November, 1969, an interviewer visited grades kindergarten through 6 in all elementary schools in the Burlington, South Burlington, and Burlington Catholic school systems to obtain information about bike ownership and frequency of bike use after dark. All children were shown, first a photograph of a standard bike, next one of a high rise bike, and finally one of a high rise bike with long 'sissy' bar. A tally was made of the proportion in each grade and sex category that reported owning each type of bike, or reported owning two bikes of different types simultaneously. These figures were corrected to take into consideration children who were absent on the day the survey was made. It was assumed that the pattern of bike ownership did not change appreciably between the summer months, when patient interviews, described below, were begun and mid-November when the school survey was completed.

In addition, it was important to determine if owners of different styles of bicycles use their 
Table 1 Per cent owning bicycles of different styles by school grade among boys and girls who are bicycle owners

\begin{tabular}{|c|c|c|c|c|c|c|c|c|}
\hline \multirow[b]{2}{*}{ Bike style } & \multicolumn{8}{|c|}{ School grade } \\
\hline & $K$ & 1 & 2 & 3 & 4 & 5 & 6 & Total \% \\
\hline \multicolumn{9}{|l|}{ Boys } \\
\hline Standard & $86 \cdot 3$ & $60 \cdot 0$ & $47 \cdot 3$ & $44 \cdot 0$ & $44 \cdot 7$ & $49 \cdot 0$ & $48 \cdot 7$ & $52 \cdot 2$ \\
\hline High rise & $13 \cdot 7$ & $27 \cdot 4$ & $39 \cdot 9$ & $45 \cdot 0$ & $41 \cdot 0$ & $35 \cdot 5$ & $28 \cdot 2$ & $34 \cdot 2$ \\
\hline High rise, 'sissy' bar & 0.0 & $10 \cdot 5$ & $10 \cdot 4$ & $8 \cdot 5$ & $8 \cdot 4$ & $8 \cdot 0$ & $12 \cdot 5$ & 8.9 \\
\hline Standard and high rise & 0.0 & $2 \cdot 1$ & $2 \cdot 4$ & $2 \cdot 5$ & $5 \cdot 8$ & $7 \cdot 5$ & $10 \cdot 6$ & $4 \cdot 7$ \\
\hline $\begin{array}{c}\text { Total }^{\circ}{ }_{\circ} \text { of owners }{ }^{\star} \\
(\mathrm{N})\end{array}$ & $\begin{array}{l}100 \cdot 0 \\
(233)\end{array}$ & $\begin{array}{l}100 \cdot 0 \\
(430)\end{array}$ & $\begin{array}{l}100 \cdot 0 \\
(421)\end{array}$ & $\begin{array}{l}100 \cdot 0 \\
(402)\end{array}$ & $\begin{array}{r}99 \cdot 9 \\
(427)\end{array}$ & $\begin{array}{l}100 \cdot 0 \\
(400)\end{array}$ & $\begin{array}{l}100 \cdot 0 \\
(433)\end{array}$ & $\begin{array}{l}100.0 \\
(2746)\end{array}$ \\
\hline \multicolumn{9}{|l|}{ Girls } \\
\hline Standard & $91 \cdot 4$ & $83 \cdot 1$ & $69 \cdot 1$ & $75 \cdot 8$ & $73 \cdot 8$ & $72 \cdot 6$ & $79 \cdot 0$ & $76 \cdot 8$ \\
\hline High rise & 8.6 & $14 \cdot 7$ & $24 \cdot 9$ & $20 \cdot 3$ & $21 \cdot 8$ & $23 \cdot 8$ & $16 \cdot 4$ & $19 \cdot 4$ \\
\hline High rise, 'sissy' bar & $0 \cdot 0$ & $1 \cdot 7$ & $5 \cdot 5$ & $2 \cdot 2$ & $2 \cdot 1$ & 1.6 & $1 \cdot 6$ & $2 \cdot 3$ \\
\hline Standard and high rise & 0.0 & 0.6 & 0.5 & 1.7 & $2 \cdot 3$ & $2 \cdot 1$ & $3 \cdot 0$ & 1.5 \\
\hline Total ${ }^{\circ}$ of owners* & $100 \cdot 0$ & $100 \cdot 1$ & $100 \cdot 0$ & $100 \cdot 0$ & $100 \cdot 0$ & $100 \cdot 1$ & $100 \cdot 0$ & $100 \cdot 0$ \\
\hline 0 & (221) & $(300)$ & $(401)$ & (355) & (389) & (383) & (371) & $(2480)$ \\
\hline
\end{tabular}

*In this and subsequent tables, total per cents may not equal 100 because of rounding out of decimal places. Per cents are rounded to the nearest decimal place if $N \geqslant 100$, and to the nearest whole number if $\mathrm{N}<100$
Basic information was obtained from the hospital records about the nature of the event and the injuries. The mother of each injured child was then visited by a trained interviewer in order to obtain further information about the circumstances of the event, type of bicycle, an estimate of level of activity and risk taking behavior by the child relative to other children the same age and sex, and parental interest and participation in various sports. If the injured child was a passenger on the bike, the information about the event, riding experience, activity and parental interests was obtained from the mother of the child who actually was in control of the bike. All such mothers interviewed seemed quite knowledgeable about the event itself even though their own children hadn't been injured.

A total of 107 relevant injuries were identified in the four month period through hospital records. Interviews were completed with the mothers (or in one case, the babysitter who took care of the child after the event) concerning 104 of these. Two additional mothers refused to be interviewed, and follow up was impossible of a third case because the family had left town.

(4) In the fourth step a child the same age, sex, and neighbor wund of residence was matched with the injured child, or with the driver, where the injured child was a passenger. The match was obtained by asking the mother of the injured child (or of the driver) at the completion of the interview to name the child living nearest who was the same age and sex as the injured child (or the driver). All such matches were within a year or two of the age sought. The mother of the comparison child was interviewed with reference to her own child, was asked all of the questions asked about the injured child except those that were irrelevant for the comparison sample, because they involved the injury event. A total of 99 such interviews were completed. Two additional mothers refused to be interviewed, and three further children were not matched because the injured person was a child, but the operator of the bike was above age 12 .

In the analysis, injury rates were computed using injuries from Burlington and South Burlington only, since denominator information was available only from these two communities. All injuries, no matter what the town of residence in the Burlington area, were used in comparing relative proportions among children who had been injured (or had been in control of a bike at the time a passenger was injured) and children of same age, sex, and neighborhood who owned bikes but had not been injured on them during the four months of the study. Where appropriate, data were analyzed by means of the $\chi^{2}$ test to determine the statistical significance of differences observed.

\section{Results}

PATTERNS OF OWNERSHIP

A total of 4698 children were surveyed in the Burlington and Burlington Catholic School Systems and 1364 in the South Burlington 
School System. By the time they reach kindergarten two thirds of children own bikes. Ownership rises during the first two grades and becomes stable from grades 2 through 6 , with 80 to $90 \%$ of children owning bikes. Overall, one third of bikes owned are high rise style. Ownership of high rise bikes is much greater among boys than among girls (table 1). The survey of the prevalence of bike use according to style suggests that both styles of bicycle are used about equally often by their owners.

For children who still owned their first bikes, the age at which they learned to ride was compared with the wheel size of the bike. This is shown in table 2 .

Significantly more high rise bikes were less than one year old, and owners of high rise bikes who had been injured were significantly more likely $(\mathrm{p}<0.05)$ to have a new bike than were owners of such bikes in the comparison group. Among bike owners in injury events, $70 \%$ of standard bikes and $43 \%$ of high rise bikes were first bikes, whereas $47 \%$ and $32 \%$ respectively were first bikes among comparison group owners with standard and high rise styles. Both groups, of course, were similar in age, and both the injury and the comparison groups respectively learned to ride two wheeled bikes at mean ages of 5.8 and 5.9 years.

\section{PATTERNS OF BICYCLE USE}

When the school survey was carried out children were asked if they ever rode their bikes after dark. Table 3 shows the proportion of boys and girls in each community who state they ride their bikes after dark.

Seventy eight per cent of respondents to the registration questionnaire report that the bike is ridden by only one child, with no difference observed between standard and high rise styles. The older the child, the more likely is he to share it with others. Thus, $19 \%$ of children age 6 or under, $21 \%$ of those age 7 through 9 , and $29 \%$ of children age 10 through 12 were reported to share their bikes.

\section{INJURY RATES}

Four month injury rates per 1000 bike owners were determined for Burlington and South Burlington since denominator information about ownership was available only for these two communities. The four month injury rates appear in table 4 . Actually, the total bike riding season in this area extends from early April to

Table 3 Per cent by school grade of boys and girls who ride bicycles after dark in Burlington and South Burlington

\begin{tabular}{|c|c|c|c|c|c|c|c|}
\hline \multirow[b]{2}{*}{ Location } & \multicolumn{7}{|c|}{ School grade } \\
\hline & $\bar{K}$ & 1 & 2 & 3 & 4 & 5 & 6 \\
\hline \multicolumn{8}{|l|}{ Burlington } \\
\hline $\begin{array}{l}\text { Boys } \\
\text { Girls }\end{array}$ & $\begin{array}{l}17 \cdot 6 \\
19 \cdot 4\end{array}$ & $\begin{array}{l}31 \cdot 6 \\
19 \cdot 7\end{array}$ & $\begin{array}{l}31.0 \\
17 \cdot 6\end{array}$ & $\begin{array}{l}31.3 \\
19.5\end{array}$ & $\begin{array}{l}35 \cdot 3 \\
21 \cdot 2\end{array}$ & $\begin{array}{l}37.8 \\
30.9\end{array}$ & $\begin{array}{l}57 \cdot 1 \\
35 \cdot 8\end{array}$ \\
\hline \multicolumn{8}{|l|}{$\begin{array}{l}\text { South } \\
\text { Burlington }\end{array}$} \\
\hline $\begin{array}{l}\text { Boys } \\
\text { Girls }\end{array}$ & - & $\begin{array}{l}50 \cdot 5 \\
39 \cdot 7\end{array}$ & $\begin{array}{l}39 \cdot 6 \\
28 \cdot 1\end{array}$ & $\begin{array}{l}43 \cdot 1 \\
29 \cdot 9\end{array}$ & $\begin{array}{l}49 \cdot 6 \\
21 \cdot 9\end{array}$ & $\begin{array}{l}50 \cdot 5 \\
32 \cdot 4\end{array}$ & $\begin{array}{l}68 \cdot 9 \\
41 \cdot 2\end{array}$ \\
\hline
\end{tabular}

Table 4 Four month injury rates by age, sex, and bicycle style per 1000 owners of bicycles in Burlington and South Burlington

\begin{tabular}{llll}
\hline Data & $\begin{array}{l}\text { No of } \\
\text { bicycle } \\
\text { owners }\end{array}$ & $\begin{array}{l}\text { No } \\
\text { of } \\
\text { injuries }\end{array}$ & $\begin{array}{l}\text { Injuries/ } \\
1000 \\
\text { owners }\end{array}$ \\
\hline Age & & & \\
5 & 609 & 7 & $11 \cdot 5$ \\
6 & 790 & 11 & $13 \cdot 9$ \\
7 & 822 & 10 & $12 \cdot 2$ \\
8 & 757 & 9 & $11 \cdot 9$ \\
9 & 816 & 11 & $13 \cdot 5$ \\
10 & 783 & 6 & $7 \cdot 7$ \\
11 & 804 & 5 & $6 \cdot 2$ \\
12 & 804 & 8 & $10 \cdot 0$ \\
Boys & 3267 & 49 & $15 \cdot 0$ \\
Girls & 2918 & 20 & $6 \cdot 9$ \\
Both sexes & 6185 & 69 & $11 \cdot 2$ \\
Standard bikes & & & \\
Boys & 1808 & 25 & $13 \cdot 8$ \\
Girls & $2283 \cdot 5^{\star}$ & 13 & $5 \cdot 7$ \\
Both sexes & $4001 \cdot 5^{\star}$ & 38 & $9 \cdot 3$ \\
High rise bikes & & & \\
Boys & 1459 & 24 & $16 \cdot 4$ \\
Girls & $634 \cdot 5^{\star}$ & 7 & $11 \cdot 0$ \\
Both sexes & $2093 \cdot 5^{\star}$ & 31 & $14 \cdot 8$ \\
\hline
\end{tabular}

*Owners of two bikes of different styles were considered to use each bike for one half of their riding.

late November; therefore, the injury rates reported can reasonably be estimated to be one half the annual injury rates. This, slightly over $2 \%$ of bicycle owners in this age range can be expected to have medically treated injuries each year involving moving bicycles.

Boys had significantly higher injury rates per 1000 users than did girls, a pattern that is quite consistent with the greater occurrence of all injuries among boys. It is not clear whether in this case boys have higher injury rates because they use their bikes more often than girls, because they use them in different ways, or a combination of these reasons.

Injury rates for children ages 5 through 9 were somewhat, but not significantly higher than for those ages 10 through 12 . Surprisingly, however, the rate among 5 year olds, virtually all of whom could be considered to be learners, was no higher than for those age 8 or 9 , almost all of whom already had several years of riding experience. No injuries were observed among 4 year olds from Burlington or South Burlington, although almost $15 \%$ of children learn to ride by this age. It may be that children who are athletically most competent learn to ride at the youngest age, a question considered later, or that greater riding skill at ages 8 and 9 is offset by more 'daredevil' riding behavior. It is also possible that real differences were missed because of the small sample size of injuries in each age group, although if the phenomenon of greater risk at certain ages were strong enough (for example, a twofold increase) it should have shown up despite the smallness of the sample.

Injury rates per 1000 owners of high rise bikes were somewhat higher than for owners of standard bikes. These differences were not significant, however, for either sex. In contrast to the determination of injury rates, the comparison of bike styles of the injured and the uninjured serves to identify retrospectively whether one style was overexpressed in injuries when used by persons of similar age, sex, and 
area of residence. Sixty one per cent of bikes involved in injuries were of standard style in comparison with $52 \%$ of bikes owned by uninjured neighbors matched for age and sex. These proportions, which were based upon all 104 injuries instead of only those from Burlington and South Burlington, again do not suggest that high rise bikes were overrepresented in injury events. The consistency in results between these two methods suggests that in fact no difference exists between the two types of bike.

\section{TYPES OF INJURY}

The types of injuries incurred on the two styles of bicycles were compared. Two thirds of the children injured had only abrasions, contusions, or lacerations. About $20 \%$ of injuries were fractures, and 5\% concussions. No difference was observed between bike styles in distribution of severity of injury. However, $22 \%$ of children on high rise bikes, but only $10 \%$ on standard bikes, had injury to the head only $(p=0.07)$.

Contact with the ground was responsible for the majority of injuries. Most really seriously injuries - that is, concussions and fractures occurred from contact with objects other than the bike itself. However, the frequency of injury from bicycle wheels was unanticipated, 14 persons having had injury from this source. The major reason for this becomes apparent when the mechanism of the event is examined. In 18 of the 104 injury events the bicycle carried both a driver and a passenger, and the passenger was injured in 17 of these. Contact with the wheel was the cause of the injury in nine of these injuries, and contact with the drive chain was the cause in a 10th case. In the remaining wheel injuries, the rider's foot slipped off the pedal and into the spokes.

\section{MECHANISM OF EVENT}

All injuries occurred either during full daylight or, rarely, at dusk. The circumstances involved in the event were compared for standard and high rise bikes and are shown in table 5 . Although a wide range of circumstances appears to be involved, two major differences can be observed between events involving standard and high rise bikes. A significantly larger proportion of injuries on standard bikes were involved in collisions with automobiles, while horseplay was a factor in a significantly larger proportion of events on high rise bikes. Although the exact numbers have not been documented, it is however relevant that several mothers spontaneously commented that the handlebars on their children's bikes were loose and that this may have contributed to loss of control. Fewer than $5 \%$ of all injuries involved riding 'no hands'.

Thirty seven per cent of the injuries occurred to individuals who were not riding their own bikes. In $34 \%$ of these 38 cases the individual was riding someone else's high rise, and in $66 \%$ he was riding someone else's standard bike. Forty one per cent of injuries to persons on
Table 5 Circumstances leading to event among injuries to children with standard and high rise bicycles

\begin{tabular}{llc}
\hline & \multicolumn{2}{c}{ Type of bicycle } \\
\cline { 2 - 3 } Circumstances of event & Standard & High rise \\
\hline Lost control, no apparent reason & $5^{\circ} \%$ & $10^{\circ} \circ$ \\
Lost control while attempting to turn & 5 & 7 \\
Lost control while attempting to stop & 8 & 5 \\
Hit obstruction & 19 & 15 \\
Horseplay & 13 & 29 \\
Distracted & 10 & 2 \\
Foot caught in bike & 11 & 10 \\
Part of bike broke & 3 & 2 \\
Rode too close to stationary object & 8 & 10 \\
Panic in presence of car or other & 8 & 2 \\
$\quad$ hazard & 6 & 0 \\
Car initiated event & 5 & 7 \\
Other & $101(63)$ & $99(41)$ \\
Total \% (N) &
\end{tabular}

their own bikes involved high rise style. Children who owned high rise bikes were about as likely to borrow standard bikes as were those who owned standard bikes to borrow the high rise style.

As noted earlier, passengers were present in about one injury out of every six. Some form of loss of control was a factor in $37 \%$ of injuries involving passengers, and another $32 \%$ involved a foot getting caught. In contrast, loss of control was a factor in $26 \%$ of injuries without a passenger, and feet were caught in only $6 \%$. Horseplay was a factor in $11 \%$ of events with passengers and $21 \%$ involving unaccompanied drivers.

Over three quarters of injuries involving passengers occurred on borrowed bikes. In many cases the owners of these bikes had permitted friends or siblings to borrow the bikes and were sitting behind them as passengers. Thus the driver not only had to handle a bike with which he may have been relatively unfamiliar, but he also had to do so while carrying additional weight. The end result of this arrangement commonly was that the owner got injured.

Seventy three injuries occurred to persons riding on smooth roads, 14 on dirt or gravel roads, and 17 in fields, on paths, or other places without roads. In $18 \%$ of injuries on smooth roads or on non-road surfaces, but $57 \%$ of those on gravel or dirt roads, the mechanism of the event was loss of control while attempting to turn or because an obstacle in the road was struck.

\section{CHARACTERISTICS OF BICYCLE OWNERS AND} THEIR PARENTS

It was hypothesized that children in the injury group more often would be reported as excessively active and daring, and would tend to have sportsminded parents. A further hypothesis was that active, risk taking children with active parents would be more likely to own high rise bikes.

In response to questions about activity level, mothers in both the injury and comparison groups rated their children equally. There is an obvious skewing towards reporting by mothers that their children - whether boys or girls are more active than others the same age and 
sex. Put in other words, most mothers are sure their children are the world's most active, or pretty nearly so. However, apparently they can distinguish between amount of activity and that which involves risk taking, because in both the injury and comparison groups, a fairly normal distribution curve of level of daring was reported.

Children who own high rise bikes, whether in the injury or comparison group, more often are reported by their mothers to be very active in comparison to children who own standard bikes.

No differences were observed in level of activity or daring, or in style of bike owned according to the parents' interest in sports. Activity scale did seen to be related to age at which children learn to ride $(0 \cdot 10<\mathrm{p}<0 \cdot 15)$. Thus, children who were rated less active than their peers comprise respectively $4 \%, 5 \%, 8 \%$, and $17 \%$ of those who learned to ride at age 4 or under, 5,6 , and 7 or older. No such differences were observed according to daring scale.

Where both parents are sports oriented, children learn to ride a bike at an early age ( 5 or younger), whereas if neither parent is interested in sports they often don't learn until aged 7 or later $(p<0.05)$. If only one parent is interested in sports, the age at which the child learns is greater than if both parents are interested, but a bit earlier than if neither is interested.

\section{Discussion}

As is documented in this report, the recent changes in the form of the high rise style so far have made themselves felt much more among boys than among girls, despite the fact that, judging by frequency of ownership, the bicycle itself is an equally popular form of recreation for both sexes.

Some of the observations of this study were disturbing, others reassuring. Among those in the former category is the small, but excessive, number of children who have bikes apparently too large for them to handle properly. For example, among children who learned to ride at age 6 and who still had their first bikes, $22 \%$ had bicycles with $26^{\prime \prime}$ wheels.

A second point of concern is the relatively large proportion of children who state that they ride their bikes at night, despite the rarity of operational lights on bikes this investigator has observed at night. It was indeed a surprise, therefore, to find that all injuries occurred during daylight hours, an observation somewhat at variance with a recent study of collisions between bicycles and automobiles in North Carolina. ${ }^{3}$ The absence of injuries after dark may perhaps be attributed to the fact that the present study was not limited to collisions with automobiles, and in fact included rather few of these events. Also, the study covered only half of the bike riding season, including months with long hours of daylight. Furthermore, although many children may occasionally ride after dark, the nighttime exposure still may comprise only a very small proportion of the total hours of exposure.

Regarding the injury pattern, there does not appear to be any strong evidence in this study that high rise bikes are more hazardous than the standard style, either in greater frequency or severity of injury despite concern on theoretical grounds that such hazard exists. The total sample of injuries admittedly is small, so that modest but real differences might conceivably not appear to be statistically significant. The fact that there is such consistency between two different methods for comparing rates, and no differences in severity, however, suggests that in fact the new style is not more hazardous, despite a contrary conclusion by the National Commission on Product Safety ${ }^{4}$ based entirely on anecdotes and engineering theory rather than epidemiologic data.

Two possible areas for stylistic change which could improve the safety record of the product do deserve consideration. The first results from the frequency of injury to legs and feet by wheels, especially the spokes. A recent paper has indicated that many of these injuries are more serious than originally estimated upon initial examination at time of injury. ${ }^{5}$

Admittedly, a large proportion of these injuries result from what an adult would call misuse of the bike, such as riding double, borrowing bikes, speeding downhill, and so forth. The frequency of such activities associated with the injuries observed is one of the important conclusions of this study. More important, however, the prime consumers of the product - that is, children who are still learning to balance caution and action apparently do not commonly consider such behavior to represent misuse. As long as a product is made for a consumer, it must be reasonably responsive to the types of demands that can be anticipated will be made by the consumer. And, according to a recent study of bicycle games played by children, the demands may be quite varied. ${ }^{6}$ With this in mind, it appears reasonable to examine the potentials and implications of other less damaging mechanisms that can substitute for spokes in maintaining the integrity of the wheel, or that can reduce the hazard of spokes when they break.

The second area for stylistic change is the handlebar and the fork within which it rests. Mothers spontaneously mentioned several times that the handlebars were loose, a situation that would not occur if the surfaces at which the bars and fork are held were flattened instead of being perfectly round. This would require only minimal changes in the manufacturing process, certainly far more minimal than the changes required to design and market the high rise style. In this investigator's experience, it is quite easy for handlebars and forks to loosen and get out of alignment during the process of normal, condoned use of bikes. Such loosening can be anticipated to occur much more often if the bike is used for 'wheelies' (riding momentarily on the rear wheel only), a maneuver that is accomplished more easily and therefore more frequently with the high rise bike.

Adding to the likelihood that bike parts will loosen is the fact that many, if not most bikes as well as other toys - offered for sale in recent 
years come unassembled and must be put together by an army of mechanically uneducated fathers, often with inadequate equipment for the task at hand. Originally, when unassembled toys were sold, they tended to be accompanied by 'throw away' tools of the appropriate sizes, Even this assistance is no longer the rule. It is perfectly clear that rising labor costs and profit squeeze are largely responsible for these changes that put more burden on the consumer. It is also clear, however, that the unwanted consequences go considerably beyond the harried look that many fathers have the day after they purchase a new toy for their children.

Children who learn to ride at an early age are mostly likely to be active children, presumably with more advanced neuromuscular development. Furthermore, they more often have parents who are intensely interested in sports and are likely to supervise their learning endeavors. This may explain why injury rates are similar during the four youngest years of bicycle ownership, again assuming that real differences haven't been overlooked because of small sample size. Parents, in general, seem to use reasonable judgement in permitting their children to ride only when they appear to be capable of doing so without undue hazard.

\section{Summary}

A study was made of bicycle ownership among over 6000 children ages 5 through 12 in Burlington and South Burlington, Vermont, and of all medically treated injuries over a four month period involving moving bicycles to children in this age range who lived in Burlington and surrounding communities. A total of 104 such injuries were studied. The injured children were compared with uninjured neighbors matched for neighborhood, age, and sex.

Ownership of two wheeled bicycles rises rapidly beginning at about age 4 , until it stabilizes by age 7 , with eight or nine out of every 10 children owning bicycles. Children, both of whose parents are interested in sports, are much more likely to learn to ride at age 5 or younger, while those with neither parent interested in sports more often learn at age 7 or older. Boys are more likely to own high rise bicycles than are girls. Overall, two thirds of bicycles owned are standard style and one third are high rise. The high rise bicycles tend to be more recent purchases.

Slightly over $2 \%$ of bike owners are injured on moving bicycles each year, with boys having significantly higher injury rates than girls. Injury rates are fairly stable for ages 5 through 9 and slightly lower during ages 10 through 12 . Thirteen per cent of injuries - usually involving two persons on the bicycle - resulted from contact with the wheel. Thirty seven per cent of the injuries involved persons on borrowed bicycles.

High rise bicycles do not appear to be more hazardous than standard bicycles. However, modification of bicycle wheels to reduce injurious contact with spokes and of handlebars to reduce the frequency of loosening appears warranted.

Joanne Gobrecht, Elinor Rosenstein, Judy Bromberg, and Dr Elbert B Whorton of the Department of Community Medicine collaborated in various phases of the study. Appreciation is expressed to the Medical Center Hospital of Vermont, the staffs of the Burlington and South Burlington School Departments, the Burlington Catholic elementary schools, and the South Burlington Police Department for assistance in this project.

1 Howell TR. Accidents and those bizarre bicycles. Pediatrics 1968; 42: 214

2 Bannister ET. (Royal Society for the Prevention of Accidents), Letter to National Commission on Product Safety, May 8, 1969.

3 Waller PF, Reinfurt DW. Bicycles: an analysis of accidents in North Carolina. Chapel Hill, North Carolina: University of North Carolina Highway Safety Research Center 1969.

4 Final Report of the National Commission on Product Safety. Washington DC, US Government Printing Office, June 1970.

5 Bicycle spoke injuries. BMF 1969; iv: 182.

6 Vilardo FJ, Nicol MJ, Heldreth HE. Kids and bikes. Traffic Safety 1969; 69(2): 8. 